\title{
Changing trends: an overview of increasing burden of fungal infections from a tertiary care hospital in Punjab (north India)
}

\author{
Shivani Tyagi *, Aroma Oberoi , Vipin Sam Alexander, Sangeetha Mohan \\ Department of microbiology, Christian medical college and hospital, Ludhiana \\ *Corresponding authorE-mail: dr_shivani_tyagi@yahoo.com
}

Copyright $\odot 2014$ Shivani Tyagi et al. This is an open access article distributed under the Creative Commons Attribution License, which permits unrestricted use, distribution, and reproduction in any medium, provided the original work is properly cited.

\begin{abstract}
Background: Fungal infections are an emerging group of infections particularly affecting immunocompromised individuals and those with indwelling medical devices. Spectrum of fungal pathogens is wide which include yeasts like Candida and Cryptococcus and filamentous fungi like Aspergillus and Zygomycetes.

Materials and methods: A retrospective study was conducted over a period of five years in the department of Microbiology in a tertiary care hospital in North India. Various clinical samples were collected from the patients presenting with clinically suspected fungal infections. Direct microscopy with potassium hydroxide (KOH) was done to visualize the presence of fungal elements and Gram staining was done for any suspected yeast infection. Fungal cultures of all samples were inoculated on Sabourauds dextrose agar (SDA).

Results: A total of 5724 clinical samples with suspected fungal etiology were received in the Microbiology laboratory during the study period. From a total of 689 isolates which came positive, Candida sp. was the most common isolate accounting for 520 (75.4\%), followed by Aspergillus species 110 (15.9\%), Mucor species 34 (4.9\%), Cryptococcus species $9(1.3 \%)$, Penicillium species 8 (1.2\%), Dermatophytes 4 (0.6\%), Fusarium sp. $3(0.4 \%)$ and Acremonium sp. $1(0.1 \%)$

Conclusions: Fungal infections share a good amount in the burden of increased morbidity and mortality in the diseased. Regular surveillance studies are important to determine the prevalence of different fungal infections in various centers.

Keywords: Fungus, candida, aspergillus, zygomycetes, India.

\section{Introduction}

In this century of ever growing medicine and advancing therapeutic technologies in the form of antimicrobial drugs, surgical procedures, transplantation medicine and invasive monitoring devices, there has been a definite increase in the survival of the diseased, but this boon has brought along with it the ever rising risk of acquiring fungal infections by the people at the user end of these therapeutic ventures [1]. Fungal infections are a significant and growing public health problem today, especially among the severely immunocompromised individuals which include those with HIV infection, hematologic malignancies, recipients of immunosuppressive therapies and solid-organ or hematopoietic stem cell transplantation, burns or indwelling medical devices and low-birth-weight infants [1]. Spectrum of these fungal infections ranges from those caused by Candida, Cryptococcus, and Aspergillus to Zygomycetes. Newer fungal pathogens like non-albicans Candida, various species of Zygomycetes and Penicillium species are also being increasingly reported over the last 10 years [2], [3]. Anatomical barriers like skin and mucosa are the first line of defense against infectious pathogens. These barriers are broken down during surgery, invasive procedure or when indwelling catheters are used. Moreover, burns, chemotherapy, radiotherapy and graft-versus-host disease can damage the skin or cause mucosal lesions thereby allowing fungal agents to reach the tissues and blood and produce infection [2], [3]. With the increasing use of these treatment modalities and thereby the increased risk of associated fungal infections, it is important for us to have knowledge about the prevalence of different fungal pathogens in our hospital settings to define our management strategies for proper treatment plan \& infection control. The objective of this study was to assess the changing patterns of different types of fungal infections in our tertiary care hospital.
\end{abstract}




\section{Material \& methods}

A retrospective study was done in the Department of Microbiology of Christian Medical College \& Hospital, Ludhiana. A total of 5724 samples of pus, sputum, Broncho alveolar lavage (BAL), bile, periorbital tissues, nasal swab, corneal scraping, cerebrospinal fluid (CSF), pleural fluid, ascitic fluid and wound swabs received in the lab over a period of five years from 1st October 2007 to 31st October 2012 were included in the study as shown in Table 1.

The samples were subjected to direct microscopy with $10 \%$ potassium hydroxide (KOH) wet mount and Gram stain to demonstrate yeast like cells, hyphae and pseudohyphae. All samples were cultured on Sabourauds dextrose agar (SDA). The mycological identification was based on macroscopic and microscopic examination of the culture isolates. The macroscopic examination of dermatophytes \& filamentous growth was characterized by duration of growth, surface morphology and pigment production on the reverse. The microscopic examination of filamentous fungal growth was observed with lactophenol cotton blue stain [4]. Oval budding yeast like cells resembling Candida on Gram staining were speciated by germ tube test, production of chlamydospores on corn meal agar \& colour of colonies on CHROM agar [4]. Spherical \& budding yeast forms resembling Cryptococcus species were identified by standard procedures [4]. The results were considered positive when smear results were consistent with culture, or growth of the organism was demonstrated on two or more occasions with negative smear results, or repeated appearance in smear with negative culture results.

Table 1: Percentage distribution of specimens received in mycology section

\begin{tabular}{ll} 
& Table 1: Percentage distribution of specimens received in mycology section \\
\hline Samples & Percentage $(\%)$ \\
\hline Sputum & 47 \\
Tissue & 10 \\
Pleural and ascitic fluid & 0.9 \\
BAL & 8 \\
CSF & 7 \\
Pus & 3.3 \\
Corneal scrapings & 4 \\
Laryngeal \& throat swab & 1.2 \\
Wound swab & 1.9 \\
Cava fix tip & 0.6 \\
\hline
\end{tabular}

\section{Results}

The frequency distribution of samples from clinically suspected fungal infections from various clinical departments is given in Table 1 . The most frequent sample received was sputum in around $47 \%$ of total samples followed by tissue biopsy samples (10\%), bronchoalveolar lavage (BAL) (8\%), cerebrospinal fluid (CSF) (7\%) and corneal scraping (4\%). The annual frequency of different clinical samples in which fungi was demonstrated by direct microscopy, culture or both is given in Table 2. A total of 689 (12\%) samples were positive for the presence of fungi. The comparison of microscopy and culture of various clinical samples is shown in Table 3; both positive $43(0.8 \%)$, only microscopy positive $117(2 \%)$ and only culture positive $537(9.4 \%)$.

From a total of 689 isolates, Candida sp. was the most common isolate accounting for 520 (75.4\%), followed by Aspergillus species 110 (15.9\%), Mucor species 34 (4.9\%), Cryptococcus species 9 (1.3\%), Penicillium species 8 (1.2 $\%)$, Dermatophytes $4(0.6 \%)$, Fusarium sp. $3(0.4 \%)$ and Acremonium sp. $1(0.1 \%)$ as shown in the fig. The detailed distribution of the frequency of isolation of the fungi across the study period is given in Table 4.

\section{Discussion}

In one of the studies, the most common invasive fungal infections were candidiasis (53\% of all invasive fungal infections found) followed by invasive aspergillosis (19\%), cryptococcosis (8\%), non-Aspergillus molds (8\%) and Zygomycosis (2\%) [5]. In another study, Candidiasis accounted for 50\% of the total infections followed in order by Cryptococcus (7\%), and finally all other fungal or mold infections combined accounted for $37 \%$ of the total. The findings in our study are almost comparable.

More than 200 species of Candida have been described, but only a few have been implicated in human disease like C. albicans, C. glabrata, C. parapsilosis, C. tropicalis and C. krusei [6], [7], [8], [9]. The concern about Cryptococcus species has also dramatically increased as it is one of the most common life threatening fungal infections in HIV patients. Aspergillosis encompasses a broad spectrum of diseases caused by members of the genus Aspergillus. Zygomycosis has emerged as an increasingly important infection, particularly among hematopoietic stem cell transplant recipients and patients with haematological malignancies. In addition to causing disease in these severely immunocompromised individuals, Zygomycosis can also cause lethal infections in a broader population, including patients with diabetes mellitus [10], [11], [12]. Although Candida and Aspergillus species remain the most common 
pathogens, the spectrum of invasive mycoses is changing with emergence of other opportunistic fungal pathogens such as Zygomycetes and Cryptococcus species [13], [14], [15].

Table 2: Annual frequency of various clinical samples which were suspected for fungal infections

\begin{tabular}{lllllll}
\hline & $2007^{\mathrm{a}}$ & 2008 & 2009 & 2010 & 2011 & $2012^{\mathrm{b}}$ \\
\hline Sputum & 20 & 57 & 85 & 73 & 67 & 37 \\
Endotracheal aspirate & 1 & 16 & 16 & 27 & 35 & 16 \\
BAL & 3 & 13 & 5 & 10 & 15 & 6 \\
Wound Swab & 2 & 0 & 7 & 2 & 1 & 1 \\
Tissue & 1 & 9. & 22 & 13 & 13 & 14 \\
Pus & 0 & 3 & 12 & 6 & 5 & 3 \\
Corneal scraping & 0 & 6 & 7 & 7 & 6 & 1 \\
Nail & 0 & 1 & 3 & 4 & 11 & 1 \\
Skin & 0 & 0 & 0 & 2 & 0 & 0 \\
CSF & 0 & 0 & 0 & 0 & 0 & 0 \\
Pleural and ascitic fluid & 0 & 0 & 3 & 2 & 0 & 1 \\
Others & 0 & 6 & 2 & 2 & 3 & 5 \\
\hline
\end{tabular}

\section{Legend / Footnote:}

a) Includes samples from 1st October, 2007 to 31st December, 2007.

b) Includes samples from 1st January, 2012 to 31st October, 2012.

c) Others include Chest drain tube, ear swab, Buccal scraping, conjunctival scraping and Nasal secretions.

Table 3: Year wise correlation between direct microscopy and culture in clinical samples

\begin{tabular}{llll}
\hline & Direct microscopy alone & Culture positive & Direct microscopy + Culture positive \\
\hline $2007^{\mathrm{a}}$ & 5 & 21 & 2 \\
2008 & 10 & 101 & 2 \\
2009 & 28 & 128 & 8 \\
2010 & 23 & 110 & 9 \\
2011 & 31 & 114 & 16 \\
$2012^{\mathrm{b}}$ & 20 & 63 & 6 \\
Total $(\%)$ & $117(2 \%)$ & $537(9.4 \%)$ & $43(0.8 \%)$ \\
\hline
\end{tabular}

\section{Legend / Footnote:}

a) Includes samples from 1st October, 2007 to 31st December, 2007.

b) Includes samples from 1st January, 2012 to 31st October, 2012.

Table 4: Annual frequency of fungal isolates in different clinical samples (2007-2012)

\begin{tabular}{|c|c|c|c|c|c|c|c|}
\hline & $2007^{\mathrm{a}}$ & 2008 & 2009 & 2010 & 2011 & $2012^{b}$ & Total $(\%)$ \\
\hline Candida sp. & 24 & 91 & 112 & 101 & 128 & 64 & $520(75.5 \%)$ \\
\hline Aspergillus sp. & 4 & 16 & 30 & 25 & 20 & 15 & $110(15.9 \%)$ \\
\hline Mucor sp. & 0 & 3 & 12 & 7 & 6 & 6 & $34(4.9 \%)$ \\
\hline Cryptococcus & 0 & 0 & 2 & 2 & 4 & 1 & $9(1.3 \%)$ \\
\hline Penicillium sp. & 0 & 0 & 5 & 3 & 0 & 0 & $8(1.2 \%)$ \\
\hline Dermatophytes & 0 & 1 & 0 & 1 & 2 & 0 & $4(0.6 \%)$ \\
\hline Fusarium sp. & 0 & 1 & 2 & 0 & 0 & 0 & $3(0.4 \%)$ \\
\hline Acremonium & 0 & 0 & 1 & 0 & 0 & 0 & $1(0.1 \%)$ \\
\hline
\end{tabular}

\section{Legend / Footnote:}

a) Includes samples from 1st October, 2007 to 31st December, 2007.

b) Includes samples from 1st January, 2012 to 31st October, 2012. 


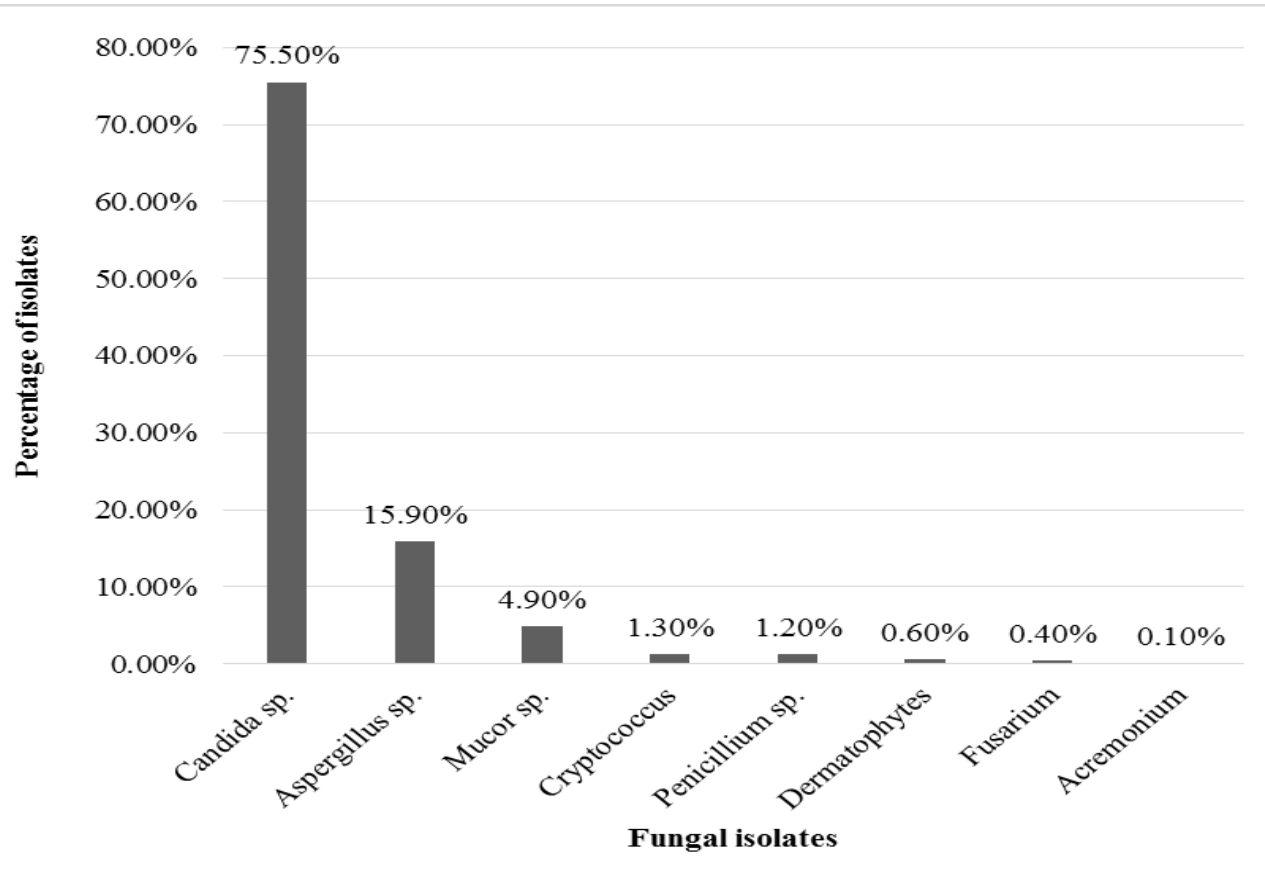

Fig. 1: Distribution of different species of fungi from different clinical specimens during the study period (2007-2012).

\section{Conclusion}

It is apparent that these fungal infections share a good amount in the burden of increased morbidity and mortality in the diseased and more so when these are still underdiagnosed. Regular surveillance studies to determine prevalence of different fungal infections in various centers can help in building up a national data base and finding out the true magnitude of the problem posed by them, thereby helping us to prioritize research, diagnostic and prevention efforts.

\section{References}

[1] Clark TA, Hajjeh RA. Recent trends in the epidemiology of invasive mycoses. Curr Opin Infect Dis. 2002 Dec; 15(6):569-74.

[2] Richardson MD, Warnock DW. Fungal Infection: Diagnosis and Management, 3rd edn. Oxford: Blackwell publishing, 2003.

[3] Richardson M. Changing patterns and trends in systemic fungal infections. J Antimicrob Chemother. 2005 Sep; 56 Suppl 1:i5-i11.

[4] Winn WC et al. Mycology. Koneman's Color Atlas and Textbook of Diagnostic Microbiology. 6th edition. USA: Lippincott Williams and Wilkins; 2006: p. 1156-232.

[5] Pappas PG, Alexander BD, Andes DR, Hadley S, Kauffman CA, Freifeld A, et al. Invasive fungal infections among organ transplant recipients: results of the Transplant-Associated Infection Surveillance Network (TRANSNET). Clin Infect Dis. 2010 Apr 15; 50(8):1101-11. doi: $10.1086 / 651262$.

[6] Colombo AL, Nucci M, Park BJ, Nouer SA, Arthington-Skaggs B, da Matta DA, et al. Epidemiology of candidemia in Brazil: a nationwide sentinel surveillance of candidemia in eleven medical centers. J Clin Microbiol. 2006 Aug; 44(8):2816-23.

[7] Hajjeh RA, Sofair AN, Harrison LH, Lyon GM, Arthington-Skaggs BA, Mirza SA, et al. Incidence of bloodstream infections due to Candida species and in vitro susceptibilities of isolates collected from 1998 to 2000 in a population-based active surveillance program. J Clin Microbiol. 2004 Apr; 42(4):1519-27.

[8] Almirante B, Rodriguez D, Park BJ, Cuenca-Estrella M, Planes AM, Almela M, et al. Epidemiology and predictors of mortality in cases of Candida bloodstream infection: results from population-based surveillance, barcelona, Spain, from 2002 to 2003. J Clin Microbiol. 2005 Apr; 43(4):1829-35.

[9] Takakura S, Fujihara N, Saito T, Kudo T, Iinuma Y, Ichiyama S. National surveillance of species distribution in blood isolates of Candida species in Japan and their susceptibility to six antifungal agents including voriconazole and micafungin. J Antimicrob Chemother. $2004 \mathrm{Feb}$; 53(2):283-9. Epub 2003 Dec 19.

[10] Kauffman CA. Zygomycosis: reemergence of an old pathogen. Clin Infect Dis. 2004 Aug 15; 39(4):588-90. Epub 2004 Jul 30.

[11] Roden MM, Zaoutis TE, Buchanan WL, Knudsen TA, Sarkisova TA, Schaufele RL, et al. Epidemiology and outcome of zygomycosis: a review of 929 reported cases. Clin Infect Dis. 2005 Sep 1; 41(5):634-53. Epub 2005 Jul 29.

[12] Kontoyiannis DP, Lionakis MS, Lewis RE, Chamilos G, Healy M, Perego C, et al. Zygomycosis in a tertiary-care cancer center in the era of Aspergillus-active antifungal therapy: a case-control observational study of 27 recent cases. J Infect Dis. 2005 Apr 15; 191(8):1350-60. Epub 2005 Mar 16.

[13] Maschmeyer G. The changing epidemiology of invasive fungal infections: new threats. Int J Antimicrob Agents. 2006 Jun;27 Suppl 1:3-6. Epub 2006 May 16.

[14] Pagano L, Caira M, Candoni A, Offidani M, Fianchi L, Martino B, et al. The epidemiology of fungal infections in patients with hematologic malignancies: the SEIFEM-2004 study. Haematologica. 2006 Aug;91(8):1068-75.

[15] Richardson M, Lass-Florl C. Changing epidemiology of systemic fungal infections. Clin Microbiol Infect. 2008 May;14 Suppl 4:5-24. doi: 10.1111/j.1469-0691.2008.01978.x. 